\title{
COMPARAÇÃO CIRÚRGICA E HISTOLÓGICA DE CADÁVERES QUIMICAMENTE PRESERVADOS E CRIOPRESERVADOS
}

\author{
SURGICAL AND HISTOLOGICAL COMPARISON OF CHEMICALLY \\ PRESERVED AND CRYOPRESERVED CADAVERS
}

\author{
Bruno Alvarenga dos Santos ${ }^{1^{*}}$ \\ Paula Diniz Galera ${ }^{1}$ \\ Rômulo Adjuto Eloi ${ }^{1}$ \\ Marcelo Ismar Santana ${ }^{1}$ \\ ${ }^{1}$ Universidade de Brasília, Brasília, DF, Brasil. \\ “Autor para correspondência - brunoalvarenga@gmail.com
}

\section{Resumo}

Este trabalho comparou seis cadáveres de cães, sem predileção por raça, idade ou sexo, com peso entre 2 e 10 kg, provenientes da Diretoria de Vigilância Ambiental do Distrito Federal. Os cadáveres, cujos sistemas vasculares foram limpos com solução salina supersaturada, solução de Larssen modificada e água comum, foram divididos em três grupos aleatórios, respectivamente. EM seguida foram conservados com solução de Larssen modificada na proporção de $10 \%$ de seu peso corporal, objetivando-se terminar a durabilidade como modelo para o treinamento cirúrgico. Após seis sucessivos congelamentos e descongelamentos, nos quais foram realizadas cirurgias visando avaliar a resistência, cor, odor, maleabilidade e grau de autólise tecidual através de análises histológicas de coração, fígado, baço, intestino e encéfalo, ficou determinado que todos os grupos apresentaram boa qualidade para treinamento cirúrgico, permitindo cirurgias de órgãos cavitários até o terceiro descongelamento, cirurgias da conjuntiva bulbar por até quatro descongelamentos e cirurgias ortopédicas por até seis descongelamentos, ficando inviáveis a partir deste ponto, devido ao elevado grau de autólise tecidual. O grupo conservado com solução salina supersaturada se destacou por quase não desprender odor desagradável, além do encéfalo e do coração serem os únicos órgãos que praticamente não apresentaram alterações macro e microscópicas nos três primeiros descongelamentos.

Palavras-chave: ética animal; método alternativo de ensino; solução de Larssen modificada; treinamento cirúrgico.

\begin{abstract}
This study compared six dog cadavers, with no predilection for breed, age, or sex, weighing between 2 and 10 $\mathrm{kg}$, from the Environmental Monitoring Directory of the Federal District, Brazil. Animals were divided into three random groups. The vascular systems were cleaned with supersaturated saline, modified Larssen solution, and common water, respectively, followed by preservation with modified Larssen solution at $10 \%$ of body weight, aiming to determine the durability as a model for surgical training. Surgeries were performed in the period between six successive freezing and thawing cycles to evaluate the resistance, color, odor, flexibility
\end{abstract}


and degree of tissue autolysis through histological analysis of heart, liver, spleen, intestine, and brain. All the groups showed good quality for surgical training, allowing cavity organs surgeries until the third thawing, bulbar conjunctiva surgeries until the fourth thawing, orthopedic surgeries for up to the sixth thawing, becoming unworkable from this point, due to the high degree of tissue autolysis. The group of cadavers preserved with supersaturated saline solution stood out by hardly giving off unpleasant smell; in addition, brain and heart are the only organs that practically did not show macroscopic and microscopic changes in the first three thawing cycles.

Keywords: alternative teaching method; animal ethics; modified Larsson solution; surgical training.

Recebido em: 30 de julho de 2014.

Aceito em: 27 de abril de 2018.

\section{Introdução}

Com o desenvolvimento das políticas de bem estar animal, passou-se a se ponderar sobre o uso de animais vivos para o ensino, os limites de atuação do ser humano para com eles, bem como a redução de seu uso nessas práticas ${ }^{(1)}$. No entanto, ainda vemos no Brasil cursos de Medicina Veterinária que recorrem à vivissecção para fins didáticos ${ }^{(2)}$, fato que vai contra as atuais políticas de uso ético de animais e a formação de médicos veterinários mais conscientes, responsáveis e qualificados ${ }^{(3,4)}$; pois existem métodos alternativos a essa prática como os simuladores virtuais ${ }^{(5)}$, materiais sintéticos ${ }^{(6)} \mathrm{e}$ cadáveres quimicamente preservados ${ }^{(7)}$.

Entretanto, o uso de modelos virtuais e muitos dos materiais sintéticos propostos têm valor elevado para serem adquiridos $^{(8)}$, assim tem-se como alternativa mais barata a utilização de cadáveres eticamente obtidos, oriundos de óbitos por causas naturais, acidentes ou eutanasiados por doenças terminais ou lesões irreversíveis ${ }^{(9)}$ que, mesmo em locais com baixo índice de óbitos, podem ser utilizados para montar bancos de animais conservados para o ensino cirúrgico.

Em busca dessa alternativa, este trabalho teve como objetivo aprimorar a conservação de cadáveres de cães com solução salina supersaturada e solução de Larssen modificada, submetidos a múltiplos congelamentos e descongelamentos e que foram avaliados por meio de cirurgias e histologia de órgãos, visando determinar qual dentre as soluções infundidas proporcionou uma peça mais durável para o treinamento cirúrgico, bem como qual apresentou características mais próximas a de um animal vivo e que, por consequência, possa permitir o uso de um menor número de animais e proporcionar melhor formação cirúrgica aos médicos veterinários.

\section{Material e Métodos}

Foram utilizados seis cães sem predileção por raça, sexo ou idade, com pesos entre 2 e $10 \mathrm{Kg}$, provenientes da Diretoria de Vigilância Ambiental do Distrito Federal (DIVAL/DF), na qual foram eutanasiados conforme resolução $n^{0} 1000$ do Conselho Federal de Medicina Veterinária ${ }^{(10)}$. O protocolo experimental deste trabalho foi aprovado pelo Comitê de Ética no Uso Animal da Universidade de Brasília (protocolo 127542/2013).

Logo após a eutanásia, os cadáveres foram transportados ao Laboratório de Anatomia Veterinária da FAV/UnB em temperatura ambiente, onde foram identificados, pesados, higienizados e tiveram o ânus ocluído com fio náilon 3-0, utilizando sutura em padrão bolsa de fumo, para evitar extravasamento do 
conteúdo intestinal.

Em sequência, os cadáveres foram posicionados em decúbito lateral direito, sendo realizada tricotomia da região ventral do pescoço para localização e exposição da veia jugular externa e da artéria carótida comum, bem como da face medial do membro pélvico direito para exposição da veia femoral. Os vasos foram canulados após pequena incisão de suas paredes com bisturi, utilizando agulhas 40 x 16, cujas pontas foram removidas para evitar que a mesma transpassasse o vaso canulado, sendo a fixação realizada com fio de algodão.

Em seguida, os animais foram separados aleatoriamente em três grupos de igual número (grupos 1, 2 e 3), que tiveram seus sistemas vasculares limpos conforme o determinado: o grupo 1 foi higienizado com solução salina supersaturada, o grupo 2 com solução de Larssen modificada e o grupo 3 com água comum.

A solução salina supersaturada foi obtida misturando 360mg de sal comum (cloreto de sódio) em $1 \mathrm{~L}$ de água comum, sendo preparados 8L desta solução, enquanto a solução de Larssen modificada compreendeu a mistura de 100mL de Formalina a 10\%, $400 \mathrm{~mL}$ de Glicerina líquida, $200 \mathrm{~g}$ de Hidrato de Cloral, $200 \mathrm{~g}$ de Sulfato de Sódio, $200 \mathrm{~g}$ de Bicarbonato de Sódio e $180 \mathrm{~g}$ de Cloreto de Sódio dissolvidos em $2 \mathrm{~L}$ de água comum em temperatura ambiente, para formar a solução-mãe, que foi diluída em 9 L de água destilada para obtenção da solução de trabalho ${ }^{(11)}$.

As soluções de limpeza foram infundidas nos três grupos com o auxílio de frascos de solução fisiológica $(500 \mathrm{~mL})$ e equipos macro gotas, utilizando volume médio de $380 \mathrm{~mL} / \mathrm{Kg}$ e velocidade média de $46 \mathrm{~mL} / \mathrm{min}$., via artéria carótida comum e veia femoral, ou até que o líquido drenado pela veia jugular estivesse com coloração clara e sem vestígios de sangue. Após a limpeza, procedeu-se a ligadura das veias femoral e jugular com fio de algodão, dando início à perfusão da solução de Larssen modificada nos três grupos designados, via artéria carótida comum, no volume de $10 \%(100 \mathrm{~mL} / \mathrm{Kg})$ de seu peso e velocidade média de $32 \mathrm{~mL} / \mathrm{min}$. Ao término desta etapa, ligou-se a artéria carótida comum com fio de algodão, para manter a solução conservadora no interior do sistema vascular ${ }^{(12)}$.

Após a realização das manobras de preparo, os animais foram ensacados, identificados e acondicionados em freezer a $-18^{\circ} \mathrm{C}$, no intervalo máximo de 4 horas após o óbito, por um período mínimo de sete dias, para que a solução de Larssen modificada pudesse atuar nos tecidos ${ }^{(13)}$.

Como preparo pré-operatório, os cadáveres foram retirados do freezer entre 19 e 24 horas antes da utilização, para serem descongelados imersos em água comum, numa caixa d'água de $1000 \mathrm{~L}$ em temperatura ambiente. Antes dos procedimentos cirúrgicos, os cadáveres eram secados e posicionados de acordo com o procedimento.

Para uma melhor avaliação dos modelos propostos, todos os cadáveres foram submetidos a seis técnicas cirúrgicas, realizadas sempre pelo mesmo cirurgião: esplenectomia parcial, na qual se utilizou padrão de sutura simples contínuo; flap conjuntival em $360^{\circ}$, utilizando-se padrão de sutura simples interrompido não perfurante total; correção de palato mole alongado, com uso de tesoura e padrão de sutura simples interrompido; laminectomia cervical dorsal, na qual não se fechou o acesso cirúrgico; correção de luxação patelar medial, por meio do aprofundamento do sulco patelar e imbricamento da cápsula articular, utilizando-se padrão de sutura cushing para o imbricamento capsular; e reconstituição do ligamento cruzado cranial, por meio da técnica intracapsular com a fáscia lata, utilizando-se sutura em padrão simples contínuo.

Todas as suturas foram realizadas com fio monofilamentar absorvível sintético 3-0, exceto a cirurgia de 
flap $360^{\circ}$, na qual se utilizou fio monofilamentar absorvível sintético 5-0, bem como a cirurgia de reconstituição de ligamento cruzado cranial, na qual foi utilizado fio náilon 0 para fixação da fáscia lata.

Durante as cirurgias foram analisadas as características teciduais dos cadáveres submetidos às distintas soluções, atribuindo-se a eles avaliações qualitativas como a maleabilidade e a resistência tecidual, incluindo pele, vísceras, musculatura (rígida, normal ou friável) e ossos (rígidos ou quebradiços); a coloração (pálida, normal ou escura), o odor (ausente, moderado ou desagradável); a mobilidade das articulações (flácidas, normais ou rígidas), bem como a viabilidade para o treinamento cirúrgico por meio de preensões, incisões, trações e suturas teciduais.

Os congelamentos e descongelamentos foram realizados em todos os animais, por seis vezes consecutivas, respeitando-se um intervalo mínimo de sete dias ${ }^{(13)}$. Durante este período, foi realizada uma técnica cirúrgica por descongelamento, praticada na ordem proposta anteriormente sempre em um animal de cada grupo e na ordem inversa no outro animal do grupo, o que permitiu a utilização de técnicas diferentes no mesmo momento de descongelamento, além da análise histológica de baço, coração, fígado, encéfalo e intestino delgado (jejuno), em cada procedimento, através de coletas realizadas por toracotomia e celiotomia, permitindo a avaliação em diferentes níveis de autólise. As coletas de materiais para as análises histológicas foram realizadas até o momento em que os tecidos passaram a apresentar alto estado de autólise.

Os fragmentos de um centímetro de espessura coletados foram fixados em solução aquosa de formaldeído a $10 \%$ por no mínimo 48 horas para obtenção dos cortes histológicos incluídos em parafina e posteriormente corados com Hematoxilina-Eosina (HE), conforme protocolo histológico convencional $^{(14)}$. As análises foram realizadas no Laboratório de Patologia Veterinária da FAV/UnB, sendo utilizado o microscópio Leica DM 500 e câmera digital Leica ICC 50 para obtenção das imagens histológicas (Figuras 1, 3 e 6).

Para avaliação quanto ao nível de autólise dos fragmentos coletados, foram atribuídas as seguintes classificações: discreto, quando se observou manutenção das estruturas foliculares linfoides no baço, da região centrolobular e portal do fígado, das camadas mucosa, muscular e serosa no intestino, de estruturas discretamente fragmentadas e estriações normais do coração e discreta vacuolização de neurópilo (artefato) e neurônios com conformação mantida; moderado, quando se observou perda da delimitação celular (mononucleares) e padrão folicular "borrado" onde deveria haver folículos no baço, manutenção da delimitação celular, porém com perda da disposição em cordão dos hepatócitos e epitélio ductal mantido em algumas áreas no fígado, presença de separação das camadas e perda moderada da definição do epitélio no intestino, fragmentação de fibras acompanhada da manutenção das estriações do coração e perda de definição celular (neuronal) com discreta vacuolização (artefato de neurópilo no encéfalo); acentuado, com perda da definição tecidual e celular no baço, figado, intestino, coração e encéfalo, sendo ainda percebida acentuada vacuolização do encéfalo (artefato de neurópilo).

\section{Resultados}

Após o protocolo do primeiro descongelamento, foi possível observar nos animais dos grupos estudados o restabelecimento da maleabilidade e resistência da pele, órgãos e articulações e musculatura, cuja coloração era similar à observada nos mesmos tecidos de animais vivos, à exceção de pequenas áreas dos órgãos que estavam em íntimo contato com a vesícula biliar, como estômago, duodeno, jejuno e omento 
menor, as quais apresentavam coloração mais escurecida, principalmente nos animais do grupo 2 (Figura 1). Nesse descongelamento verificou-se a presença de líquido sanguinolento com odor moderado. Entretanto, após sua drenagem, verificou-se ausência de odor do modelo em todos os grupos, bem como boa resistência tecidual às incisões e suturas cirúrgicas, durante as técnicas realizadas nesse primeiro descongelamento.

A análise histológica do grupo 3 mostrou um nível de autólise moderado em todas as amostras, o grupo 2 de moderado a acentuado e o grupo 1 apresentou alteração discreta em todos os fragmentos (Figura 1).

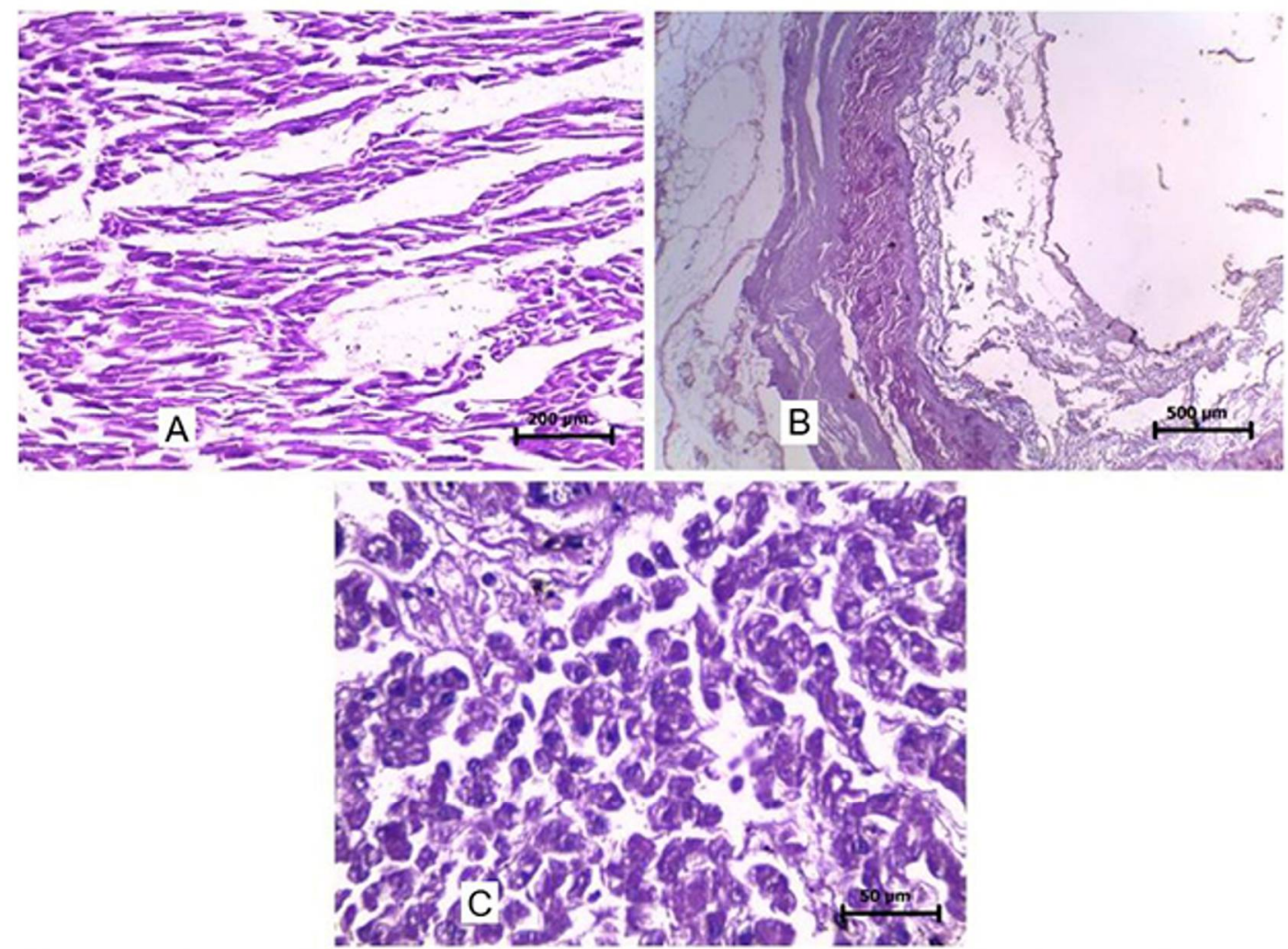

Figura 1. Imagens histológicas de baços coletados após o primeiro descongelamento, onde se observa: A) Grupo 1, com manutenção das estruturas foliculares linfoides (autólise discreta); B) Grupo 2, com separação das camadas e perda de limitação dos folículos linfoides e definição celular (autólise moderada); C) Grupo 3, com perda da arquitetura celular e da delimitação dos limites celulares (autólise acentuada).

No segundo descongelamento, as vísceras de todos os animais dos grupos estudados apresentavam coloração mais escura que a observada durante o primeiro descongelamento, mas ainda próximas do normal, salvo as áreas dos órgãos próximas à vesícula biliar, com coloração mais acastanhada. A musculatura e as articulações não apresentaram modificações significativas. Odores desagradáveis estiveram ausentes nos grupos 1 e 2 , sendo moderados no terceiro grupo.

Durante as técnicas cirúrgicas praticadas no segundo descongelamento, os tecidos e as articulações mostraram rigidez e resistência compatíveis a de animais vivos. Exceção feita à conjuntiva bulbar, que se mostrou flácida durante sua divulsão, embora ainda permitisse o treinamento cirúrgico de todos os animais estudados. Contudo, as vísceras dos animais dos grupos 2 e 3 se mostraram um pouco escorregadias, o que dificultou seu manuseio.

Durante a coleta do material para a análise histológica, os encéfalos dos animais dos grupos 2 e 3 já 
se mostraram bastante friáveis durante o toque (Figura 2), com autólise acentuada no exame histopatológico (Figura 3), enquanto que nos animais do grupo 1, o coração e o encéfalo eram os órgãos mais bem conservados, com consistência normal, sendo os únicos com grau de autólise discreto (Tabela 1; Figura 3).

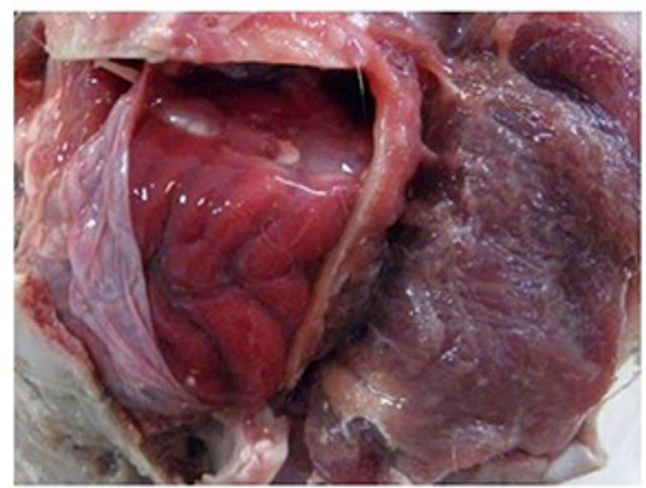

Figura 2.Encéfalo de animal do grupo 2 durante o segundo descongelamento, apresentando-se mais escuro (embebição hemoglobínica), brilhoso e com aspecto gelatinoso (autólise acentuada).
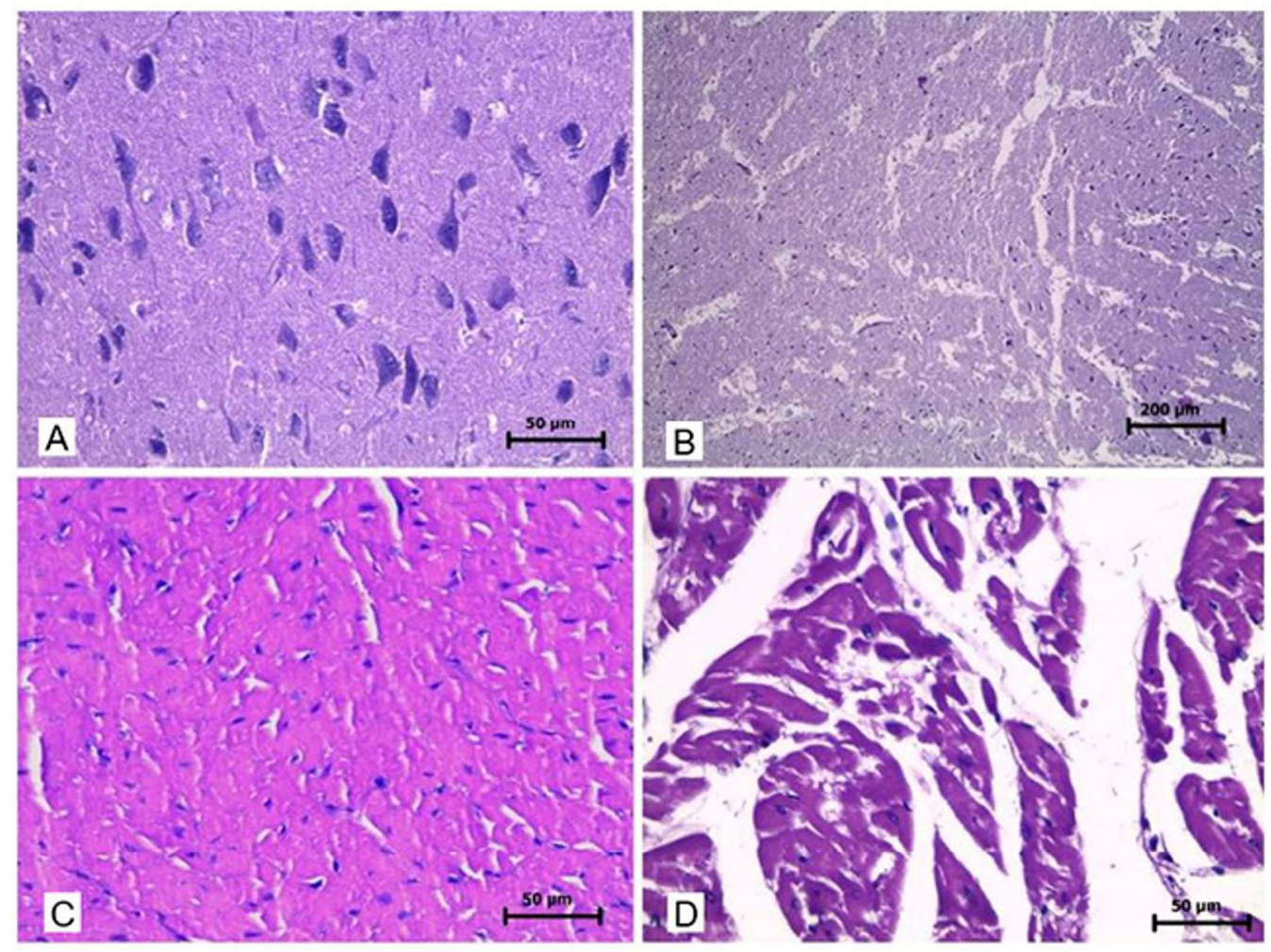

Figura 3. Imagens histológicas de amostras teciduais do encéfalo e coração, coletadas após o segundo descongelamento, onde se observa: A) Grupo 1, encéfalo com discreta vacuolização de neurópilo e neurônios com arquitetura celular e tissular mantida (autólise discreta); B) Grupo 3, encéfalo com perda de definição celular (neuronal) e acentuada vacuolização (autólise acentuada); C) Grupo 1, coração com estriações normais (autólise discreta); D) Grupo 3, coração com perda da definição tecidual (autólise acentuada).

No terceiro descongelamento, apesar dos tecidos apresentarem evidente escurecimento em todos os grupos estudados (Figura 4), foram encontradas diferenças quanto ao seu grau, pois nos grupos 2 e 3 o escurecimento 
das vísceras e da musculatura era mais acentuado que o observado nos animais do grupo 1, salvo em sua porção cervical, cuja musculatura ainda apresentava coloração próxima do normal. A conjuntiva mostrou coloração pálida em todos os animais durante o primeiro e segundo descongelamento e, no terceiro, estava branca e flácida, embora ainda permitisse o treinamento cirúrgico.

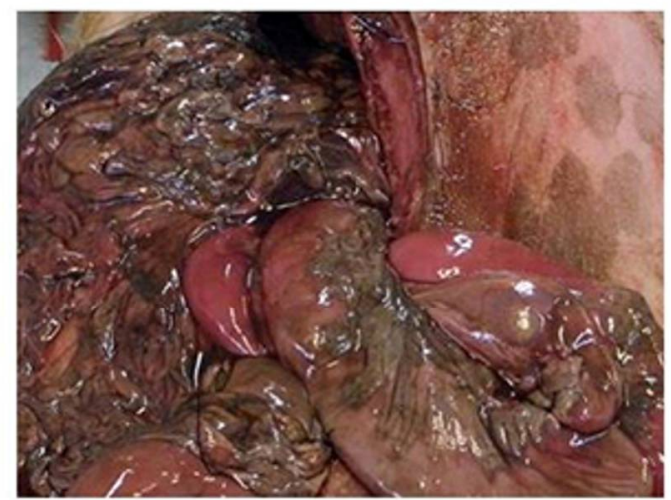

Figura 4.Vísceras enegrecidas de animal do grupo 3, com grau de autólise acentuada, durante o terceiro descongelamento.

O odor dos animais dos grupos 2 e 3 era desagradável e moderado nos animais do grupo 1 no terceiro descongelamento. Durante as técnicas cirúrgicas praticadas nos animais dos três grupos estudados, os tecidos de todas as vísceras apresentavam-se friáveis ao cerramento dos nós, observando-se laceração tecidual em todas as tentativas. Já a musculatura esquelética, bem como o palato mole se mostraram flácidos e friáveis à tração dos fios de sutura, mas ainda com resistência suficiente para o cerramento dos nós. Diferentemente dos outros tecidos, os ligamentos e a dura-máter espinhal, ainda que flácidos, apresentaram resistência e coloração próximas à observada nos dois congelamentos anteriores, bem como as cartilagens e os tecidos ósseos não mostraram alterações, mantendo ainda aspecto firme durante incisão e desgaste.

Durante a realização das coletas de materiais para a análise histológica, pôde-se perceber que os encéfalos, à exceção do grupo 1 que ainda apresentava consistência próxima à observada no descongelamento anterior $\mathrm{e}$ com discreta autólise, tinham aspecto liquefeito nos grupos 2 e 3 (Figura 5) e acentuada autólise tecidual observada durante a histopatologia (Tabela 1). Além do mais, as vísceras dos animais dos três grupos trabalhados se apresentaram bastante escorregadias, com uma película viscosa recobrindo suas superfícies, dificultando o manuseio. À exceção do coração, que ainda preservava consistência razoável, todas as outras vísceras estavam friáveis e com autólise acentuada durante o exame histológico (Tabela 1; Figura 6).

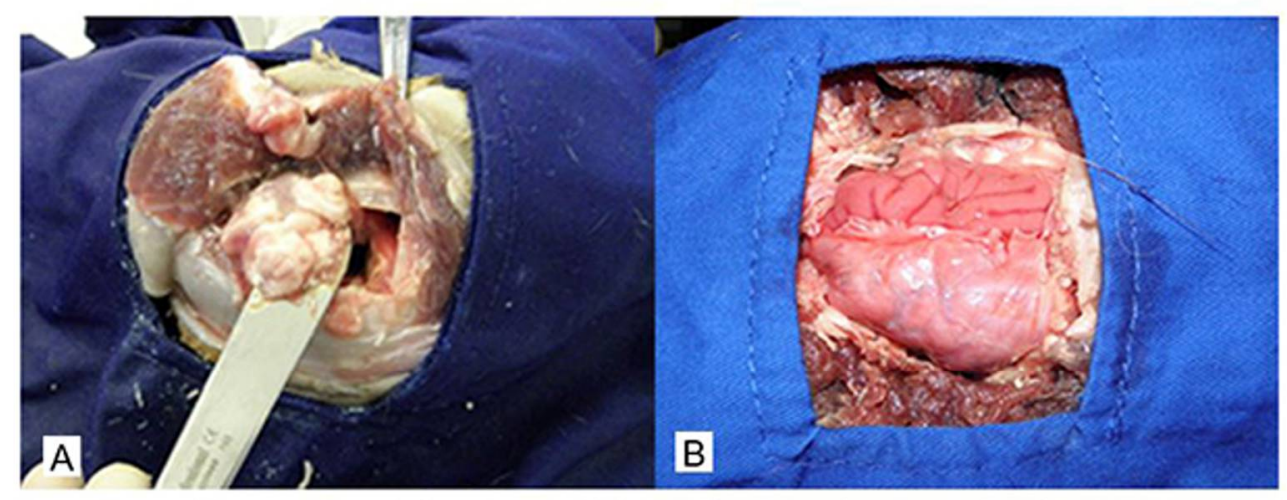

Figura5.Análise macroscópica de encéfalo realizada após o terceiro descongelamento, mostrando avançado estado de autólise em animal do grupo 2 e tecido muscular esquelético escurecido (A), em comparação ao encéfalo e musculatura esquelética em bom estado de conservação, em animal do grupo 1, ainda semelhante à coloração observada em um animal vivo (B). 


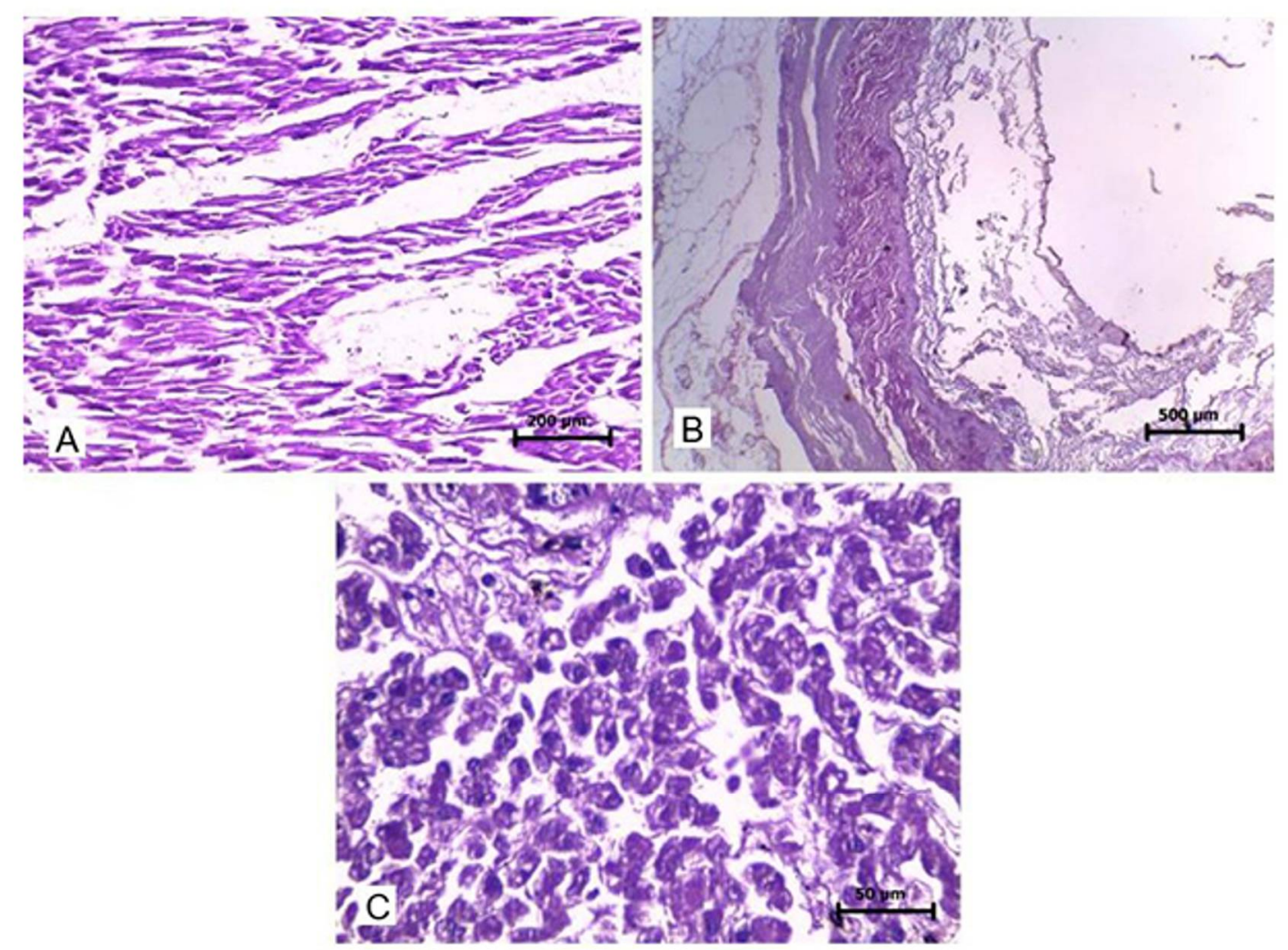

Figura 6. Imagens histológicas do grupo 3 durante o terceiro descongelamento, demonstrando perda avançada de detalhes teciduais e celulares (autólise acentuada) em: A) Coração - adelgaçamento e separação de cardiomiócitos; B) Intestino - perda completa da arquitetura tecidual e detalhes celulares e C) Fígado - perda do arranjo trabecular e de detalhes celulares dos hepatócitos.

Tabela 1. Grau de autólise caracterizado durante as análises histopatológicas das amostras, nos três primeiros descongelamentos dos animais do grupo 1, cujo sistema circulatório foi limpo com solução salina supersaturada, grupo 2 com solução de Larssen modificada e do grupo 3 higienizado com água destilada

\begin{tabular}{ccccccc}
\hline Descongelamento & Grupo & Baço & Figado & Intestino & Coração & Encéfalo \\
\hline \multirow{3}{*}{ Primeiro } & 1 & Discreto & Discreto & Discreto & Discreto & Discreto \\
& 2 & Acentuado & Acentuado & Acentuado & Moderado & Moderado \\
& 3 & Moderado & Moderado & Moderado & Moderado & Moderado \\
Segundo & 1 & Acentuado & Acentuado & Acentuado & Discreto & Discreto \\
& 2 & Acentuado & Acentuado & Acentuado & Moderado & Acentuado \\
& 3 & Acentuado & Acentuado & Acentuado & Moderado & Acentuado \\
Terceiro & 1 & Acentuado & Acentuado & Acentuado & Moderado & Discreto \\
& 2 & Acentuado & Acentuado & Acentuado & Acentuado & Acentuado \\
& 3 & Acentuado & Acentuado & Acentuado & Acentuado & Acentuado \\
\hline
\end{tabular}

No quarto descongelamento, todos os animais apresentavam as vísceras com coloração bastante enegrecida (Figura 7), musculatura esquelética com um tom vermelho escuro e ligamentos e cartilagens extremamente pálidos. Todas as vísceras estavam friáveis, pouco resistentes ao toque e totalmente inviáveis para o treinamento cirúrgico, pois se rasgavam facilmente durante a tração com pinças ou fio de sutura, além de apresentarem grande quantidade de gás em seu interior. Apesar de completamente flácidos, os músculos esqueléticos, ligamentos e cartilagens ainda apresentavam resistência suficiente para o treinamento cirúrgico 
ortopédico, suportando diferentes graus de tração e torção, enquanto o tecido ósseo praticamente não sofreu mudanças, demonstrando coloração, resistência e odor praticamente normais.

Por outro lado, o odor gerado pelas vísceras, em todos os grupos, era desagradável a insuportável, sendo moderado para musculatura e articulações. A partir deste descongelamento, foi necessário eviscerar os animais de todos os grupos trabalhados, visando sua utilização para o treinamento exclusivamente ortopédico e oftalmológico, não sendo mais possível a coleta de material para a realização da análise histológica, pois o material encontrava-se macroscopicamente em acentuado processo de autólise, sendo desnecessária a realização de histopatologia para definição o quadro.

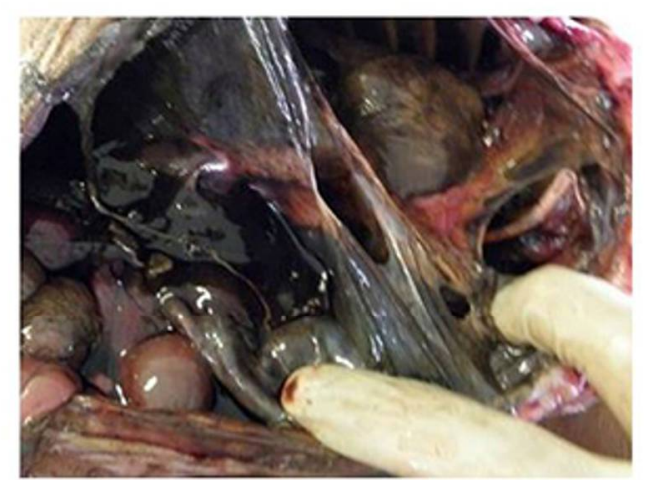

Figura 7. Cavidades torácica e abdominal após o quarto descongelamento (grupo 3), mostrando vísceras e musculatura esquelética bastante escurecidas e intestinos com grande quantidade de gás em seu interior.

No quinto e sexto descongelamento, os cadáveres eviscerados apresentavam musculatura esquelética bastante escura, ligamentos e cartilagens muito pálidos e ossos com coloração praticamente inalterada. O odor gerado pelos cadáveres era moderado em todos os grupos trabalhados.

A musculatura esquelética mostrou ser bastante friável, principalmente no sexto descongelamento, enquanto as articulações apresentaram-se completamente flácidas. No entanto, todos os tecidos ainda estavam aptos para o treinamento cirúrgico ortopédico, pois demonstravam resistência a diferentes graus de tração e torção. Porém, durante a cirurgia de flap $360^{\circ}$, observou-se que a conjuntiva bulbar estava bem flácida e friável nos dois últimos descongelamentos, rompendo facilmente quando divulsionada e suturada, tornando-se inviável para treinamento.

A partir do $7^{\circ}$ descongelamento os cadáveres não estavam mais viáveis para o treinamento cirúrgico, inclusive cirurgias ortopédicas, devido à generalizada autólise tecidual.

\section{Discussão}

Respeitou-se o período de congelamento mínimo dos cadáveres para que a solução de Larssen modificada pudesse atuar nos tecidos ${ }^{(13)}$, visando a diminuição da degradação celular em decorrência de fenômenos autolíticos ${ }^{(15)}$, enquanto a escolha das técnicas cirúrgicas selecionadas foi baseada na necessidade de se utilizar tecidos com características distintas e localizados em diferentes regiões do organismo, procurando testar sua conservação e resistência ${ }^{(19)}$, também avaliada pela autólise tecidual de órgãos com graus distintos, como coração, baço, intestinos, encéfalo e fígado ${ }^{(16)}$. 
Dessa forma, o preparo do modelo experimental mostrou-se eficiente tanto para a lavagem do sistema vascular, com esvaziamento do sangue e substituição por fluidos de limpeza, como para o embalsamamento dos tecidos com injeção da solução de Larssen modificada ${ }^{(17)}$, sendo que as diferentes técnicas de limpeza e conservação utilizadas neste trabalho proporcionaram cadáveres com boa qualidade para amplo treinamento cirúrgico (incluindo órgãos cavitários) até o terceiro descongelamento e para cirurgias ortopédicas até o sexto descongelamento, superando o período de utilização de peças descrito por Silva e Matera ${ }^{(12)}$ e Scherer ${ }^{(18)}$, que reutilizaram os animais por até quatro vezes, mantendo pele e músculos com consistência normal, mas com órgãos cavitários friáveis.

Ainda deve-se ressaltar os descritos de Matera $^{(19)}$, que utilizou cadáveres preparados de forma semelhante ao grupo 3 por até seis descongelamentos, obtendo resultados semelhantes quanto ao odor, coloração dos tecidos e flexibilidade das articulações. Não foi possível comparar os resultados obtidos para conjuntiva bulbar, já que nenhum dos autores compilados fez referência a cirurgias dessa natureza.

Quanto à modificação do tipo de líquido para a lavagem prévia do sistema vascular, ficou claro que não se acrescentou vida útil aos diferentes grupos trabalhados, vide a semelhança dos resultados macroscópicos obtidos, mas apenas se modificou a percepção de odores, pois aqueles animais preparados com solução salina supersaturada (grupo 1) e solução de Larssen modificada (grupo 2) praticamente não desprenderam odores desagradáveis até o segundo descongelamento, e odores suportáveis no terceiro, enquanto os animais do grupo 3, lavados com água, desprenderam odores desagradáveis já a partir do segundo descongelamento.

Essa diferença provavelmente pode estar relacionada com o fato de que a infusão de uma maior quantidade de sal possa desidratar levemente os tecidos, o que justificaria a maior rigidez das articulações do grupo 1 com a inibição temporária do crescimento bacteriano ${ }^{(20,21)}$, além do que, a lavagem do sistema vascular com a própria solução de Larssen (grupo 2) ajudaria na dissolução de coágulos, melhorando assim a remoção do sangue do cadáver ${ }^{(13)}$.

No entanto, as vantagens obtidas pela lavagem do sistema com solução salina supersaturada ou com solução de Larssen modificada não se mostraram duradouras, pois ainda que utilizando a última como solução conservadora, percebeu-se que sua ação antisséptica é fraca ${ }^{(13)}$, não sendo capaz de frear o crescimento bacteriano decorrente do manuseio dos animais durante o manejo entre freezer, cuba de descongelamento com água comum e o ambiente cirúrgico utilizado, fato que também pode ter contribuído para a extensa autólise visceral observada nos grupos trabalhados. Dessa forma, comprovou-se que a injeção de Solução de Larssen modificada em volume maior que $10 \%$ do peso corporal $^{(17)}$, como a utilizada no grupo 2 , não melhorou a conservação dos tecidos, mas apenas elevou os custos da preparação do material de estudo.

Mesmo não se realizando exames bacteriológicos para confirmar essa contaminação, é possível que os agentes bacterianos tenham sido os responsáveis pela autólise gradativa observada durante os descongelamentos consecutivos, causando o escurecimento das vísceras através da deposição de enxofre e pela oxidação do sangue remanescente ${ }^{(16)}$, além da difusão natural do conteúdo biliar, que também colaborou com esse processo. Ainda deve-se levar em consideração o fato de que o congelamento lento dos animais nos freezers utilizados provavelmente propiciou a formação de grandes cristais de gelo nos espaços inter e intracelular, levando a rompimento celular e maior crescimento de micro-organismos ${ }^{(22)}$, além de diminuir gradualmente a resistência dos tecidos, fato 
que ajudaria a explicar o aumento de friabilidade após os descongelamentos consecutivos.

Com a utilização das técnicas cirúrgicas selecionadas, foi possível demonstrar que os cadáveres quimicamente preservados proporcionaram um ambiente real para o aprendizado cirúrgico ${ }^{(23)}$, devido à semelhança com uma cirurgia de rotina, permitindo uma repetição de exercícios essenciais ${ }^{(17)}$, além de serem estimulantes para a prática, principalmente por manterem a cor, resistência e flexibilidade dos tecidos ${ }^{(18)}$, mesmo com a baixa durabilidade observada para as vísceras. No entanto, através da boa durabilidade apresentada pelo sistema musculoesquelético, acredita-se que a utilização desses modelos poderá ajudar na obtenção de habilidades pelos cirurgiões, sendo inclusive factível para cirurgiões com pouca experiência ${ }^{(17)}$.

Deve-se ressaltar que o grupo 1 apresentou estado de conservação ligeiramente melhor quando comparados os aspectos macro e microscópicos de encéfalo e coração, nos três primeiros descongelamentos, nos quais se mantiveram bom estado de conservação, coloração e integridade celular, semelhante à observada no primeiro descongelamento. Provavelmente, a maior quantidade de sal infundida durante a lavagem do sistema vascular acabou desidratando parcialmente o encéfalo e coração, reduzindo consequentemente a formação de cristais de água no congelamento e as lesões teciduais provenientes desta, além da autólise bacteriana ${ }^{(20,22)}$.

Outro fator de melhoria na conservação desses órgãos ainda pode decorrer da proximidade anatômica da artéria carótida comum, ponto de injeção das soluções (lavagem e conservativa) com o coração, permitindo que o órgão ficasse em contato contínuo com os fluidos durante o período de injeção. A região cervical e encéfalo provavelmente foram beneficiados pelo padrão de ramificação da aorta ascendente, já que uma parte do fluxo proveniente da artéria carótida comum alcançava rapidamente o tronco braquiocefálico, passando diretamente para a artéria carótida contralateral, retornando em direção à cabeça ao mesmo tempo em que se difundia pelo resto do corpo ${ }^{(24)}$. Dessa forma, devido à curta distância, encéfalo e coração foram reperfundidos várias vezes, enquanto as demais regiões receberiam as soluções somente após sua passagem pelo ventrículo esquerdo do coração e aorta descendente.

\section{Conclusão}

Quando comparadas as técnicas de conservação de cadáveres com uso da solução de Larssen modificada como líquido de conservação, constatou-se que, independentemente da metodologia utilizada para a limpeza do sistema vascular dos animais (solução salina supersaturada, solução de Larssen modificada ou água comum), o desempenho para a manutenção tecidual foi semelhante pois todos os cadáveres apresentaram coloração tecidual próxima a de um animal vivo até o segundo descongelamento, sofrendo escurecimento gradativo até o sexto, bem como todos os grupos estudados se mostraram apropriados para o treinamento cirúrgico de vísceras por até três descongelamentos, cirurgia da conjuntiva bulbar por até quatro e procedimentos ortopédicos por até seis, tornando-se inviáveis a partir desse número devido à generalizada autólise tecidual. A grande diferença entre os grupos estudados esteve relacionada ao odor dos cadáveres, pois os animais do grupo 1 desprenderam odores em menor quantidade quando comparados aos demais até o quarto descongelamento, quando todos passaram a apresentar odores desagradáveis, oriundos 
principalmente das vísceras.

\section{Referências}

1. Magalhães M, Ortêncio FH. Alternativas ao uso de animais como recurso didático. Arquivos de Ciências Veterinárias e Zoologia [Internet]. 2006 [Acesso Mar 2018];9(2):147-154. Disponível em: $<$ https://doi.org/10.25110/arqvet.v9i2.2006.358>. Portuguese.

2.Tudury EA, Potier GMA. Métodos substitutivos ao uso de animais vivos no ensino - métodos alternativos para aprendizado prático da disciplina técnica cirúrgica veterinária. Ciência Veterinária nos Trópicos [Internet]. 2008 [Acesso Mar 2018];11(1):92-95. Disponível em: $<$ http://revistas.bvsvet.org.br/cvt/article/view/32323/35911>. Portuguese.

3.Riveira EAB. Ética na experimentação animal. Revista de Patologia Tropical [Internet]. 2001 [Acesso Jan 2018]; 30(1):9-14. Disponível em: <https://www.revistas.ufg.br/iptsp/article/download/15790/9682>. Portuguese.

4. Rodrigues DF, Mendes FF, Silva LAF. Alternativas ao uso de animais no ensino da cirurgia veterinária e a Escola de Veterinária e Zootecnia da Universidade Federal de Goiás: revisão. Medicina Veterinária [Internet]. 2013 [Acesso Mar 2018];7(3):47-58. Disponível em:

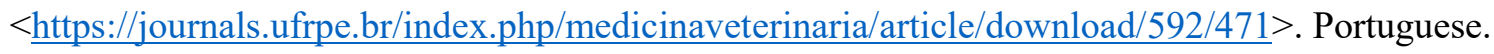

5. Pan JJ, Chang J, Yang X, Liang H, Zhang JJ, Qureshi, T, et al. Virtual reality trainingand assessment in laparoscopic rectum surgery. International Journal of Medical Robotics and Computer Assisted Surgery [Internet]. $2015 \quad$ [Acesso Mar 2018];11:194-209. Disponível em: $<$ http://onlinelibrary.wiley.com/doi/10.1002/rcs.1582/pdf $>$. English.

6. Loh CYY, Wang AYL, Tiong VTY, Athanassopoulos T, Loh M, Kao HK. Animal models in plastic and reconstructive surgery simulation: a review. Journal of Surgical Research [Internet]. 2018 [Acesso Mar 2018]; 221:232-245. Disponível em: <https://doi.org/10.1016/j.jss.2017.08.052>. English.

7. Gilbody J, Prasthofer AW, Ho K, Costa ML. The use and effectiveness of cadaveric workshops in higher surgical training: a systematic review. Annals of the Royal College of Surgeons of England [Internet].2011 [Acesso Mar 2018];9(1):347-352. Disponível em: < https://doi.org/10.1308/147870811X582954>. English.

8.Haluk RS, Krummel TM. Computers and virtual reality for surgical education in the $21^{\text {st }}$ century. ArchSurgery [Internet]. 2000 [Acesso Mar 2018]:135(7):786-792. Disponível em:

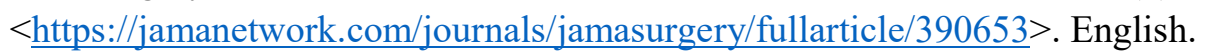

9. Jukes N, Chiuia M. From guinea pig to computer mouse: alternative methods for a progressive, humane education, 2. ed. Leicester: International Network for Humane Education; 2003. 520p. [Acesso Mar 2018]. Disponível em: <http://www.interniche.org/ru/system/files/public/Resources/Book/jukes_and_chiuia_2003 - from guinea pig to computer mouse interniche 2nd ed en.pdf.>. English.

10. Brasil. Conselho Federal de Medicina Veterinária.Resolução n ${ }^{\circ} 000$, de 11 de maio de 2012. Dispõe sobre procedimentos e métodos de eutanásia em animais e dá outras providências [Acesso Mar 2018]. Disponível em: $<$ http://portal.cfmv.gov.br/lei/index/id/326>. Portuguese.

11. Silva RMG, Matera JM, Ribeiro AACM. New alternative methods to teach surgical techniques for veterinary medicine students despite the absence of living animals. Is that na academic paradox?. Anatomia, Histologia, Embryologia [Internet]. 2007 [Acesso Mar 2018];36(1):220-224. Disponível em: 


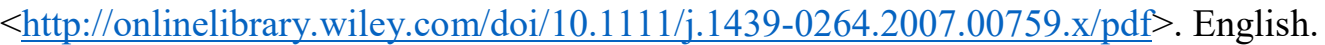

12. Silva RMG, Matera JM, Ribeiro AACM. Preservation of cadavers for surgical technique training.Veterinary Surgery [Internet]. 2004 [Acesso Mar 2018];33(1):606-608.Disponível em: $<$ http://onlinelibrary.wiley.com/doi/10.1111/j.1532-950x.2004.04083.x/pdf $>$. English.

13. Silva RMG, Matera JM, Ribeiro AACM. Avaliação do método de ensino da técnica cirúrgica utilizando cadáveres quimicamente preservados. Revista de Educação Continuada CRMV-SP [Internet]. 2003 [Acesso Mar 2018]; 6(1/3):95-102. Disponívelem: $<$ http://revistas.bvs-vet.org.br/recmvz/article/view/3263/2468>. Portuguese.

14. Timm LL. Técnicas rotineiras de preparação e análise de lâminas histológicas. Caderno La Salle XI [Internet]. 2005 [Acesso Mar 2018]; 2(1):231-239. Disponível em: $<\underline{\text { http://docente.ifsc.edu.br/leandro.parussolo/MaterialDidatico/C\%C3\%A2mpus\%20Lages/T\%C3\%A9cnico }}$ \%20em $\% 20 \mathrm{An} \% \mathrm{C} 3 \% \mathrm{~A} 1$ lises $\% 20 \mathrm{Qu} \% \mathrm{C} 3 \%$ ADmicas/Histofisiologia $\% 20$ Animal $/ \mathrm{t} \% \mathrm{C} 3 \% \mathrm{~A} 9$ cnicas $\% 20$ histo $1 \% \mathrm{C} 3 \% \mathrm{~B} 3$ gicas(2).pdf $>$. Portuguese.

15. Hamazaki S, Koshiba M, Habuchi T, Takahashi R, Sugyiama T. The effect of formalin fixation on restriction endonuclease digestion of DNA and PCR amplification. Pathology Research and Practice [Internet]. 1993 [Acesso Mar 2018]; 189(5): 553-557. Disponível em: <https://doi.org/10.1016/S0344-0338(11)80365$1>$. English.

16. Jones TC, Hunt RD, King NW. Patologia veterinária. 6. ed. São Paulo: Manole; 2000. 1415p. Portuguese.

17. Menezes CLMM. Preservação de cadáver de coelho (Oryctolaguscuniculus) com a solução de Larssen modificada para treinamento em cirurgia videolaparoscópica [Dissertação]. Porto Alegre: Universidade Federal do Rio Grande do Sul; 2012. 82p. [Acesso Mar 2018] . Disponível em: $<$ http://www.lume.ufrgs.br/bitstream/handle/10183/49944/000851761.pdf? sequence=1 $>$. Portuguese.

18. Scherer S. Desenvolvimento de modelo experimental em cadáver de cão conservado com solução de Larssen modificada para treinamento em videocirurgia: Nefrectomia total e tireoidectomia [Dissertação]. Porto Alegre: Universidade Federal do Rio Grande do Sul; 2009. 78p. [Acesso Mar 2018]. Disponível em:

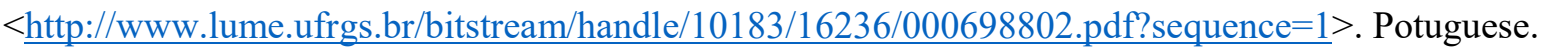

19. Matera JM. O ensino de cirurgia: da teoria à prática. Ciência Veterinária nos Trópicos [Internet]. 2008 [Acesso Mar 2018];11(1):96-101. Disponível em: <http://www.rcvt.org.br/suplemento11/96-101.pdf> Portuguese.

20. Brun MV, Pippi NL, Dreimeier D, Contesini EA, Beck CAC, Cunha O et al. Solução hipersaturada de sal como conservante de pericárdio canino utilizado na reparação do músculo reto abdominal de ratos wistar. Ciência Rural [Internet]. 2002 [Acesso Mar 2018]; 32(6):1019-1025), 2002. Disponível em: $<$ http://www.scielo.br/pdf/cr/v32n6/12748.pdf $>$. Portuguese.

21. Sant'ana APF, Dias ICG, Saddi LGC et al. Utilização do formaldeído, em diferentes concentrações, associado ou não ao cloreto de sódio, na conservação de tecidos de ovinos. In: Congresso Brasileiro de Medicina Veterinária [Internet]; 2008. [Acesso Mar 2018]. Disponível em: $<$ http://www.sovergs.com.br/conbravet2008/anais/cd/resumos/R1277-1.pdf $>$. Portuguese.

22. Colla LM, Hernández CP. Congelamento e descongelamento - sua influência sobre os alimentos, Vetor [Internet].2003 [Acesso Mar 2018];13(1):53-66. Disponível em: $<$ http://www.repositorio.furg.br/bitstream/handle/1/6803/428-742-1-PB.pdf? sequence=1 $>$. Portuguese.

23. Simforoosh N, Khazaeli M, Nouralizadeh A, Soltani MH, Samzadeh M, Saffarian O et al. Laparoscopic animal surgery for training without sacrificing animals; introducing the rabbit as a model for infantile laparoscopy. Journal of Laparoendoscopic \& Advanced Surgical Techniques [Internet]. 2011 [Acesso Mar 
2018]; 21(10):929-933. Disponível em: <https://www.liebertpub.com/doi/pdf/10.1089/lap.2011.0308>. English.

24. Martins MD, Lima AR, Pinheiro LL, Santa Brígida SS, Araújo EB, Melul R et al. Descrição morfológica dos ramos colaterais do arco aórtico e suas principais ramificações em Leopardus pardalis. Acta Veterinaria Brasilica [Internet]. 2010 [Acesso Mar 2018]; 4(2):74-77. Disponível em:

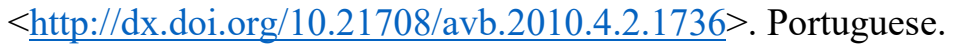

